\title{
Comparison of Hydrodynamic Coefficients obtained through Implementation of Diverse Methods in Square Tank
}

\author{
Seunghyun Kang* • + Hyeon Kyu Yoon \\ $*^{\dagger}+$ Dept. of Naval Archtecture \& Marine Engineering, Changwon National University, Changwon 641-773, Korea
}

\begin{abstract}
To confirm whether the square tank at Chang won National University (CWNU) can be used for estimation of maneuverability, planar motion mechanism (PMM) test and circular motion (CM) test were performed for various conditions. PMM test can be implemented using an XY carriage and a yaw table in the square tank. However, sometimes test section is insufficient for PMM test owing to low length-breadth ratio of the tank. In addition, the speed of a towing carriage is also quite limited. Therefore, it would be useful if PMM test could be effectively performed diagonally, by establishing coupled control logic to drive three servomotors. In addition, Froude number dependency on the estimated hydrodynamic coefficients was checked. Furthermore, CM tests, which cannot be completed in a conventional linear towing tank, were performed, and its results were compared with the results of PMM test. The results of the PMM tests in the diagonal direction were consistent with the results of the test performed in the direction parallel to the sidewall. However, the results of the CM test were greater than those of the PMM test. This tendency was also observed in the results published at Ulsan University
\end{abstract}

Key words : PMM test, CM test, square tank, hydrodynamic coefficients, Froude number

\section{Nomenclature}

$A_{y}$

$A_{\psi}$

$F, M$

Fn

$m$

$I_{z z}$

$\rho$

$u, v, r$

V

$x_{0}, y_{0}$

$x_{G}$

$X, Y, N$

$X_{H}, Y_{H}, N_{H}$

$X_{T}, Y_{T}, N_{T}$

$X_{\dot{u}}, Y_{\dot{v}}, N_{\dot{r}}, \cdots$

$X_{I N}, Y_{I N}, N_{I N}$

$X_{\text {OUT }}, Y_{\text {OUT }}, N_{\text {OUT }}$

$\beta$

$\psi$

Froude number

Mass [kg]

Density $[\mathrm{kg} / \mathrm{m} 3]$

Speed $[\mathrm{m} / \mathrm{s}]$

$[\mathrm{N}, \mathrm{N} \cdot \mathrm{m}]$

Drift angle [deg]
Amplitude of Y carriage [m]

Amplitude of yaw table [deg]

Force and moment $[\mathrm{N}]$

Mass moment of inertia $\left[\mathrm{kg} \cdot \mathrm{m}^{2}\right]$

Surge, sway, and yaw velocity $[\mathrm{m} / \mathrm{s}, \mathrm{rad} / \mathrm{s}]$

$\mathrm{x}$ and $\mathrm{y}$ position of carriage coordinates

position of center of gravity [m]

Force and moment in $\mathrm{x}, \mathrm{y}, \mathrm{z}$ directions

Hydrodynamic force and moment

Towing(negative) force and moment

Hydrodynamic coefficients

In-phase force and moment

Out-of-phase force and moment

Ship's heading angle [deg]

$\begin{array}{ll}\psi_{c} & \text { Carriage running direction }[\mathrm{deg}] \\ \omega & \text { Angular rate of yaw table }[\mathrm{rad} / \mathrm{s}] \\ \cdot & \text { Time derivative } \\ \cdot & \text { Nondimensional value }[-]\end{array}$

\section{Introduction}

The captive model tests, such as the planar motion mechanism (PMM) test and circular motion (CM) test have been carried out in many institutes to understand the maneuverability of ships(Shin et al, 2009, Shin et al, 2011, Kim et al, 2009, Kim et al, 2011, Yoon and Kang, 2013, Tajima et al, 1999). Commonly, the PMM test is carried out in a linear towing tank. Although a linear towing tank is better than a square tank for performing the PMM test(Kim et al, 2009, Kim et al, 2011), some institutes, such as Changwon National University(CWNU) and Ulsan University, only have access to square tanks with PMM test facilities owing to many limitation like budget. PMM tests in a square tank have been performed at CWNU(Yoon and Kang, 2013) and Ulsan University(Shin et al, 2011) However, square tanks are not optimal for PMM tests because of the inherently low length-breadth ratio. Thus, it

* noahksh@gmail.com 055)213-3680

† Corresponding author : hkyoon@changwon.ac.kr 055)213-3683

Note) This paper was presented on the subject of "The Comparison of Hydrodynamic Coefficients obtained by Diverse Method in the Square Tank" in Asian Conference on Marine Simulation and Simulator Research 2013 proceedings, MOERI/KIOST Daejeon, Korea, 8 Aug. 2013. 
would be helpful to be able to perform PMM tests in square tanks diagonally by generating the forced coupled motion with an XY carriage and a yaw table, given that the results are sufficiently accurate. To confirm whether the diagonal PMM tests are feasible in this paper, the results of the diagonal test were compared with the results of parallel running PMM test.

In addition, PMM tests at three Froude number conditions, including 0.7, 1.0, and 1.3 times nominal Fn values, were carried out to understand the effects of varying Froude numbers(Tajima et al, 1999). It is difficult to install a high-speed carriage in the $\operatorname{tank}(\mathrm{Kim}, 2012)$, and the size of the square tank is further limited. Essentially, if the estimation of the hydrodynamic coefficients of a conventional ship is not greatly dependent on the Froude number, a square tank can be effectively used to perform PMM tests without adjusting model ship's Fn.

Furthermore, CM tests were performed using an XY carriage and a yaw table in the square tank. CM testing in square tanks(Shin et al, 2009, Shin et al, 2011) is well established and is an effective method, relative to $\mathrm{CM}$ testing in a linear towing tank. To check the feasibility of $\mathrm{CM}$ testing at CWNU, the method was performed, and its results were compared with PMM test results.

\section{Test facilty}

\subsection{Square tank}

CWNU's square tank is an academic tank that is $20 \mathrm{~m}$ long, $14 \mathrm{~m}$ wide, and $1.8 \mathrm{~m}$ deep. A towing carriage that provides linear displacement in $x_{0}$ and $y_{0}$ directions and yaw motion was installed on the tank. Fig. 1 shows the square tank and the towing carriage in CWNU. The maximum speed of the $\mathrm{X}$ and $\mathrm{Y}$ carriages are $1 \mathrm{~m} / \mathrm{s}$.

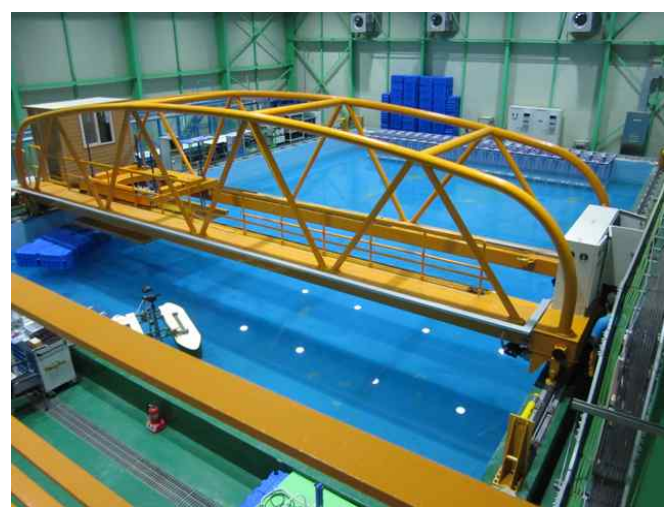

Fig. 1 Square tank and towing carriage in CWNU

\subsection{Motion mechanism}

The towing carriages consisting of an XY carriage and a yaw table were independently controlled by three servomotors. Oblique towing and dynamic motion required for the PMM and CM tests were realized even in the diagonal direction, as shown in Fig. 2.
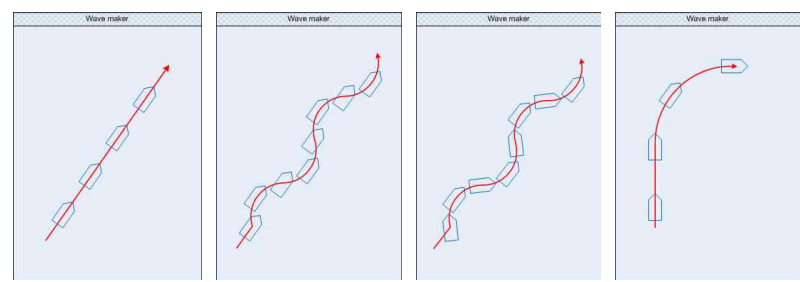

Fig. 2 Traces for diagonal PMM and CM tests

Towing trajectories of oblique towing, pure sway and pure yaw and circular motion are described as follow respectively:

$\left[\begin{array}{c}x_{0} \\ y_{0} \\ \psi\end{array}\right]=\left[\begin{array}{c}\left(V \cos \psi_{c}\right) t \\ \left(V \sin \psi_{c}\right) t \\ \psi_{c}+\beta\end{array}\right]$

$\left[\begin{array}{c}x_{0} \\ y_{0} \\ \psi\end{array}\right]=\left[\begin{array}{c}\left(V \cos \psi_{c}\right) t-\left(A_{y} \sin \psi_{c}\right) \sin \omega t \\ \left(V \sin \psi_{c}\right) t+\left(A_{y} \cos \psi_{c}\right) \sin \omega t \\ \psi_{c}+\beta+A_{\psi} \cos \omega t\end{array}\right]$

$\left[\begin{array}{l}x_{0} \\ y_{0} \\ \psi\end{array}\right]=\left[\begin{array}{c}(V / \omega) \sin \omega t \\ -(V / \omega) \cos \omega t \\ \omega t\end{array}\right]$

If the carriage run parallel to the long sidewall of the tank, $\psi_{c}$ should be zero in $\mathrm{Eq}(1)$, (2). Pure sway motion can be achieved when $A_{\psi}$ is zero in $\operatorname{Eq}(2)$, and the relation between amplitudes of the $\mathrm{Y}$ carriage and the yaw table must be satisfied when the pure yaw test is performed based on the following:

$$
A_{\psi}=\tan ^{-1} \frac{\omega A_{y}}{V}
$$

\section{Model and test conditions}

\subsection{Model}

Bare hull of KVLCC2 was selected as a test model ship(SIMMAN, 2008), because the geometry and results of 
the hydrodynamic analysis are available. The principal dimensions of the real ship and scaled model ship are listed in Table 1.

Table 1 Principal dimensions of KVLCC2

\begin{tabular}{|c|c|c|}
\hline Dimension & Real & Model \\
\hline Scale ratio & 1 & 223 \\
\hline Length between perpendiculars[m] & 320.0 & 1.4350 \\
\hline Breadth [m] & 58.0 & 0.2601 \\
\hline Draft [m] & 20.8 & 0.0933 \\
\hline Displacement [m3] & 312,622 & 0.02819 \\
\hline Block coefficient & 0.8098 & 0.8098 \\
\hline Longitudinal Center of buoyancy[\%] & 3.48 & 3.48 \\
\hline Speed [m/s] & 7.97 & 0.534 \\
\hline
\end{tabular}

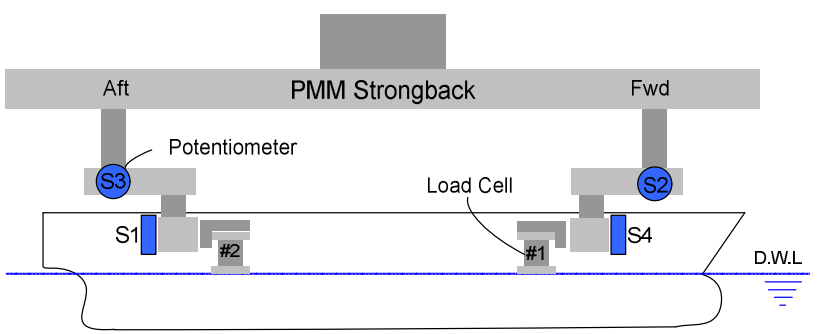

Fig. 3 Configuration of load cells and potentiometers

Fig. 3 shows both the positions of the load cells that measure the $\mathrm{X}$ and $\mathrm{Y}$ external forces and the positions of each of the potentiometers, which measure the displacements of heave and pitch at fore and after towing points. Fig. 4 shows how the PMM strongback is connected to the model.

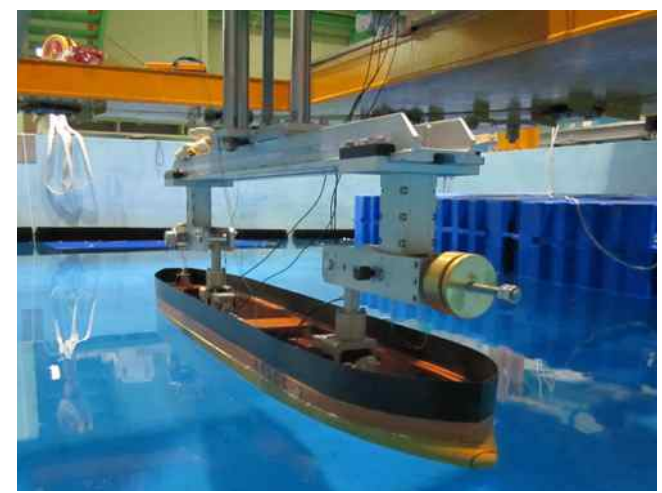

Fig. 4 Model installed on strongback

\subsection{Hydrodynamic force model}

Fig. 5 shows the coordinate systems of which are earth-fixed coordinate $\operatorname{system}\left(O-x_{0} y_{0}\right)$ and body-fixed coordinate $\operatorname{system}(o-x y)$ used in the experiment.

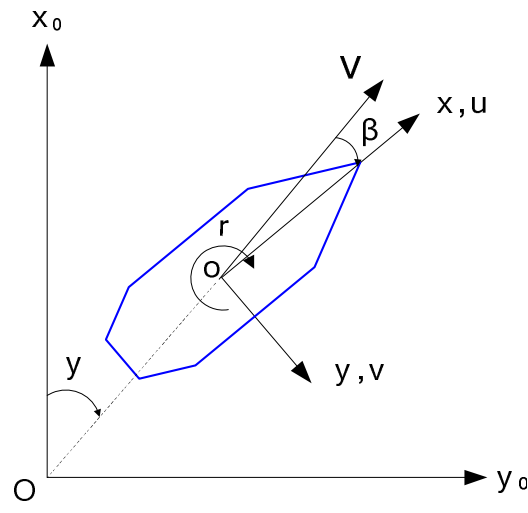

Fig. 5 Coordinate systems

Horizontal plane motion consisting of surge, sway, and yaw was considered and its equations of motion with respect to the body-fixed coordinate system are given by the following:

$$
\begin{aligned}
& m\left(\dot{u}-v r-x_{G} r^{2}\right)=X_{H}+X_{T} \\
& m\left(\dot{v}+u r+x_{G} \dot{r}\right)=Y_{H}+Y_{T} \\
& I_{z z} \dot{r}+m x_{G}(\dot{v}+u r)=N_{H}+N_{T}
\end{aligned}
$$

The hydrodynamic force and moment in Eq.(5) were modeled by the following equations, and the towing force and moment were measured by the load cells installed on the model, as shown in Fig. 3

$$
\begin{aligned}
X_{H}= & X_{\dot{u}} \dot{u}+X_{u u} u^{2}+X_{v v} v^{2}+X_{v r} v r+X_{r r} r^{2} \\
Y_{H}= & Y_{\dot{v}} \dot{v}+Y_{\dot{r}} \dot{r}+Y_{v} v+Y_{r} r \\
& +Y_{v v v} v^{3}+Y_{v v r} v^{2} r+Y_{v r r} v r^{2}+Y_{r r r} r^{3} \\
N_{H}= & N_{\dot{v}} \dot{v}+N_{\dot{r}} \dot{r}+N_{v} v+N_{r} r \\
& +N_{v v v} v^{3}+N_{v v r} v^{2} r+N_{v r r} v r^{2}+N_{r r r} r^{3}
\end{aligned}
$$

Although prime notation is not represented for convenience, ship related parameters, motion variables, external force, external moment, and hydrodynamic coefficients in Eq.(5) and (6) are non-dimensional values. Nondimensionalization was performed based on the Society of Naval Architects and Marine Engineers(SNAME) definition, as follows:

$$
F^{\prime}=\frac{F}{\frac{\rho}{2} L^{2} V^{2}}, M^{\prime}=\frac{M}{\frac{\rho}{2} L^{3} V^{2}}
$$

\subsection{Test conditions}

The test conditions for the PMM test and CM test are 
listed in Table 2 and Table 3, respectively. Diagonal tests were completed using the same conditions as those of the straight tests in which the carriage runs parallel to the sidewall.

Table 2 PMM test conditions

\begin{tabular}{|c|c|c|}
\hline \multirow{2}{*}{ Class. } & \multicolumn{2}{|c|}{ Test condition } \\
\cline { 2 - 3 } Oblique & Variable & Values \\
towing & $\beta$ & $\begin{array}{c}0^{\circ}, \pm 2^{\circ}, \pm 4^{\circ}, \pm 6^{\circ}, \\
\pm 8^{\circ}, \pm 10^{\circ}, \pm 12^{\circ}, \pm 15^{\circ}\end{array}$ \\
\hline Pure sway & $\dot{v}^{\prime}$ & $0.08,0.16,0.24,0.32$ \\
\hline Pure yaw & $r^{\prime}$ & $0.20,0.30,0.40,0.50,0.60$ \\
\hline Yaw & $\beta$ & $\pm 4^{\circ}, \pm 8^{\circ}, \pm 12^{\circ}$ \\
\cline { 2 - 3 } with drift & $r^{\prime}$ & $0.20,0.30,0.40,0.50,0.60$ \\
\hline $\begin{array}{c}\text { Froude } \\
\text { Number }\end{array}$ & $F n$ & $\times 0.7, \times 1.0, \times 1.3$ \\
\hline
\end{tabular}

Table 3 CM test conditions

\begin{tabular}{|c|c|c|}
\hline \multirow{2}{*}{ Class. } & \multicolumn{2}{|c|}{ Test condition } \\
\cline { 2 - 3 } & Variable & Values \\
\hline Circular & $r^{\prime}$ & $0.20,0.30,0.40,0.50,0.60$ \\
\hline $\begin{array}{c}\text { Circular } \\
\text { with drift }\end{array}$ & $\beta$ & $\pm 4^{\circ}, \pm 8^{\circ}, \pm 12^{\circ}$ \\
\cline { 2 - 3 } & $r^{\prime}$ & $0.20,0.30,0.40,0.50,0.60$ \\
\hline
\end{tabular}

\section{Results}

\subsection{Comparison of towing directions}

The mean hydrodynamic forces and moment measured in the oblique towing tests, which depend on the running direction, are shown in Fig. 6. The results are consistent with each other.

The in-phase hydrodynamic sway motion forces and moment to the PMM displacement and acceleration, which depend on the running direction, are shown in Fig. 7. The slopes of the test results shown in Fig. 7 represent the added mass coefficients due to sway acceleration. These coefficients are well consistent each other.

The in-phase and out-of-phase hydrodynamic forces and moments to yaw displacement and acceleration acting in the yaw direction, which depend on the running direction, are shown in Fig. 8. While the added mass coefficients are well consistent, the yaw damping coefficient a little varies. However, the trends are well consistent, and there might be small misalignments of PMM device and models.

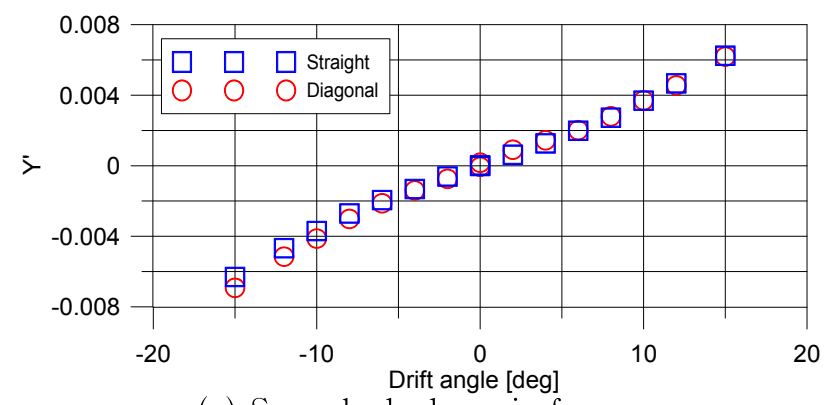

(a) Sway hydrodynamic force

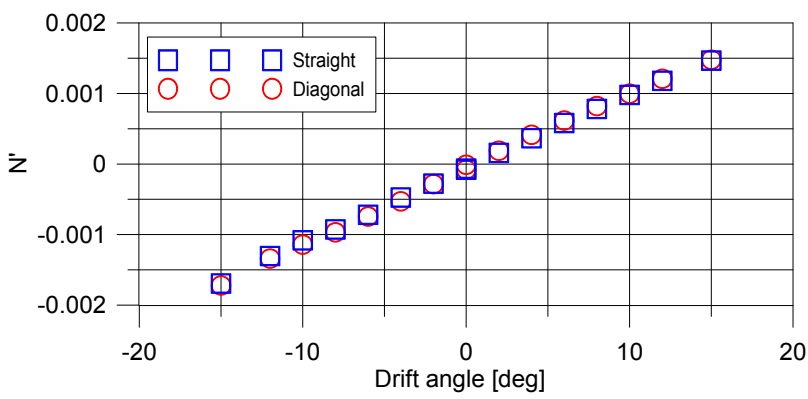

(b) Yaw hydrodynamic moment

Fig. 6 Oblique towing test results depending on running direction

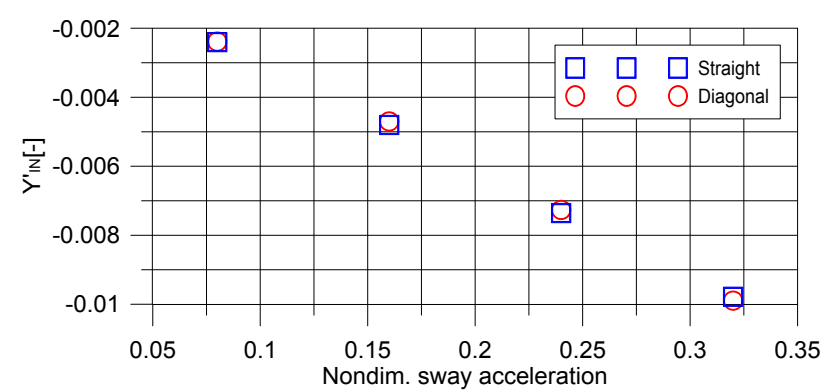

(a) Sway hydrodynamic force

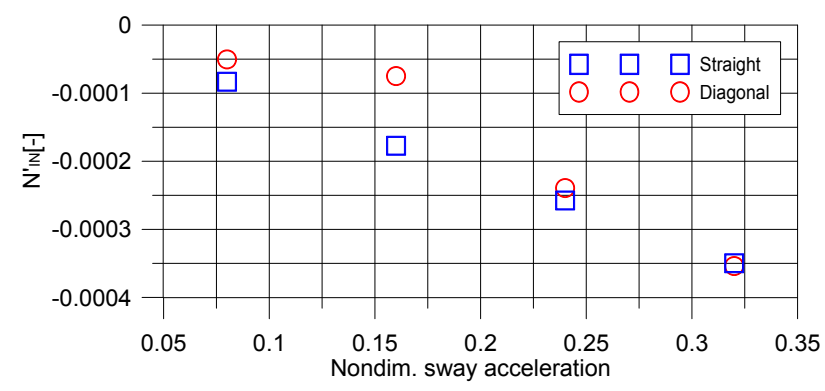

(b) Yaw hydrodynamic moment

Fig. 7 Pure sway test results depending on running direction 


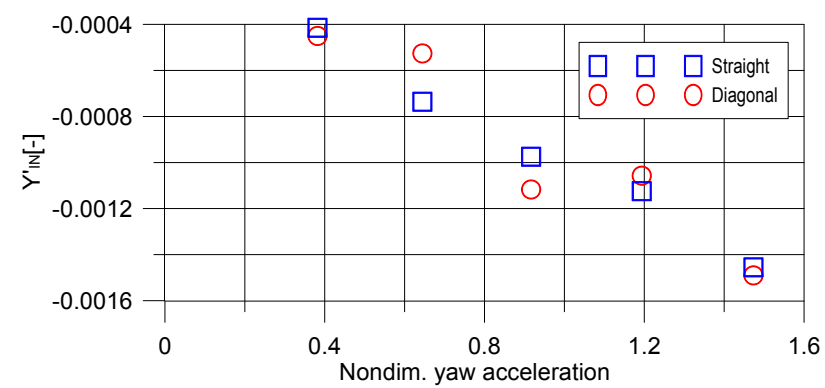

(a) In-phase sway hydrodynamic force

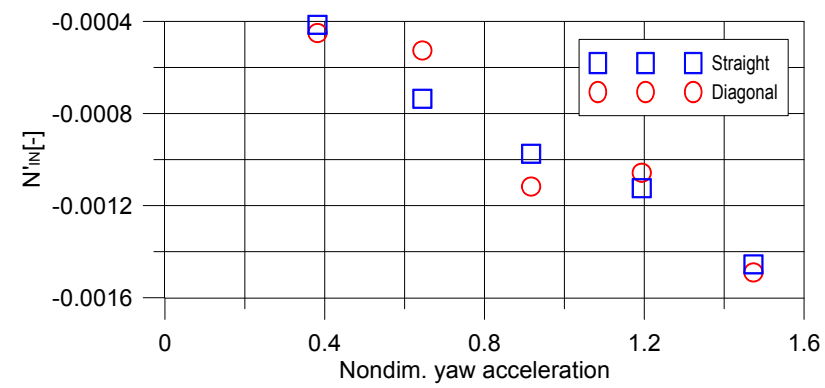

(b) In-phase yaw hydrodynamic moment

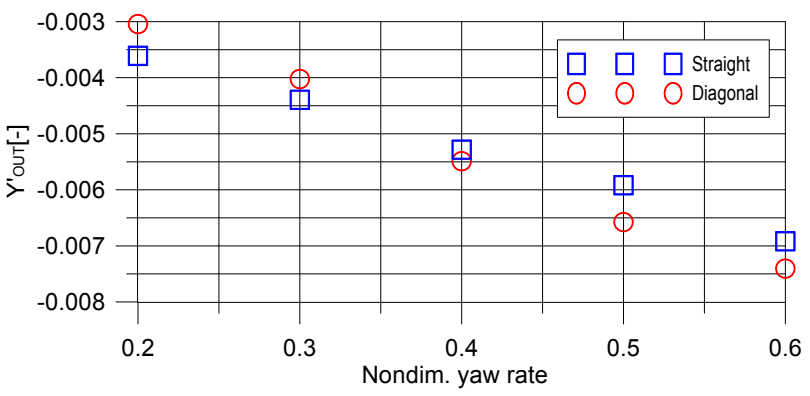

(c) Out-of-phase sway hydrodynamic force

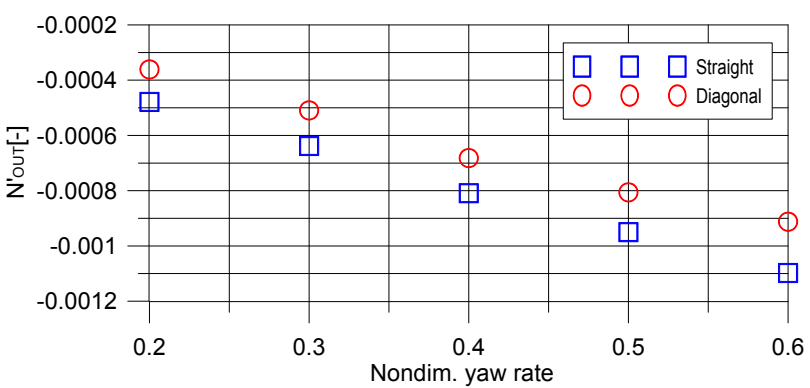

(d) Out-of-phase yaw hydrodynamic moment

Fig. 8 Pure yaw test results depending on running direction

The yaw with drift tests were performed with the same servomotor logic as the pure yaw test, except that the initial drift angle was different. The in-phase and out-of-phase hydrodynamic forces and moments acting on a ship with respect to yaw and drift motions, which depend on the running direction, are shown in Fig. 9. Even though there is a small degree of data scattering, typically the results were coincident well between the two test types.

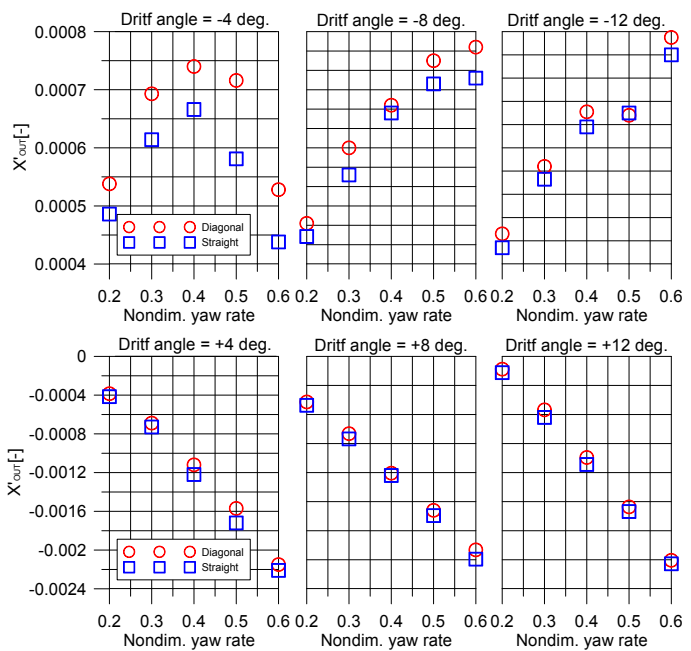

(a) Out-of-phase surge hydrodynamic force

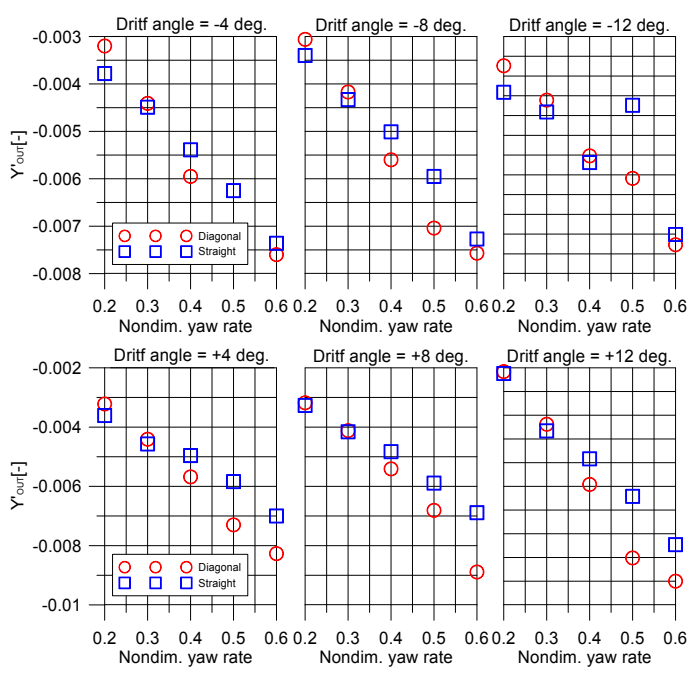

(b) Out-of-phase sway hydrodynamic force

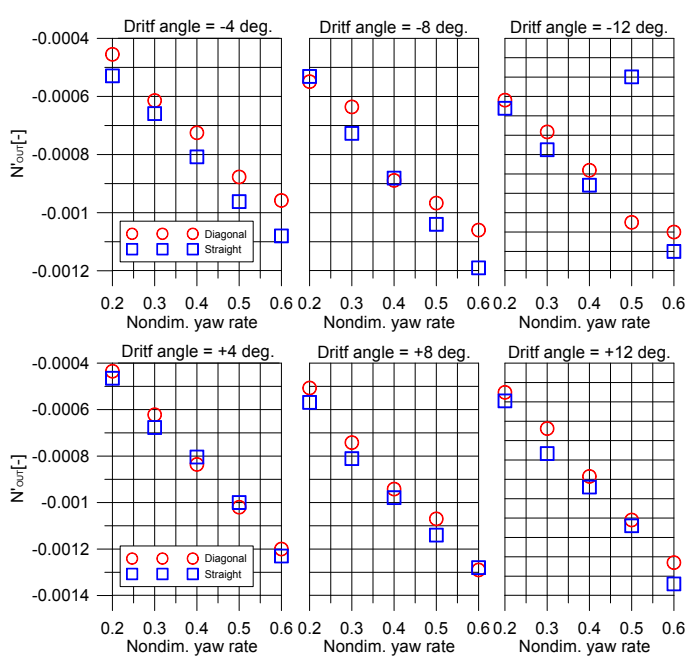

(c) Out-of-phase yaw hydrodynamic moment

Fig. 9 Yaw and drift test results depending on running direction 
Comparison of Hydrodynamic Coefficients obtained through Implementation of Diverse Methods in Square Tank

\subsection{Effects of Froude number}

The mean hydrodynamic forces and moments measured in the oblique towing tests that depended on Froude number are shown in Fig. 10. The figure shows that the differences between each Froude number are small, except in the case of large drift angles. These tests were performed in the direction parallel to the sidewall

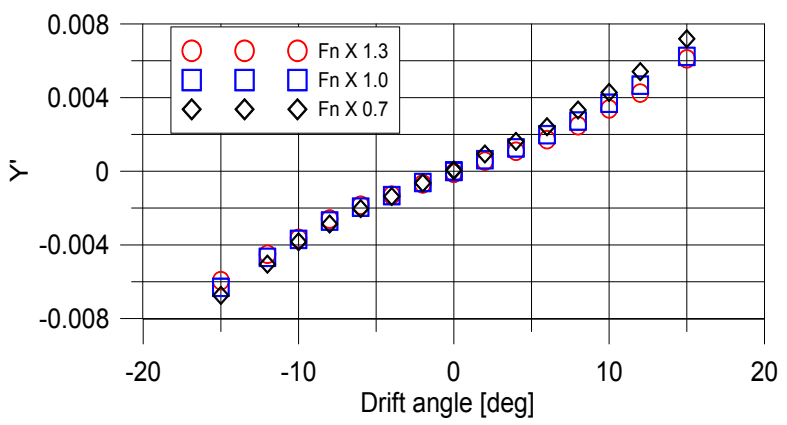

(a) Sway hydrodynamic force

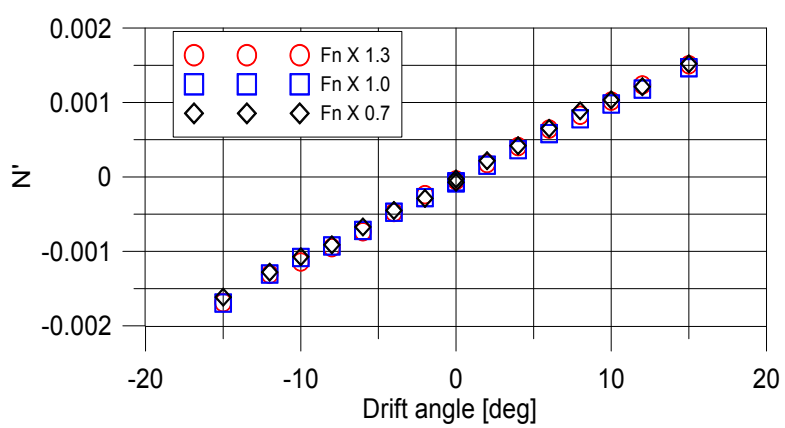

(b) Yaw hydrodynamic force

Fig. 10 Oblique towing test results dependent on $F n$

The in-phase hydrodynamic forces and moment acting on a ship in the sway motion direction, which depend on $F n$, are shown in Fig. 11.

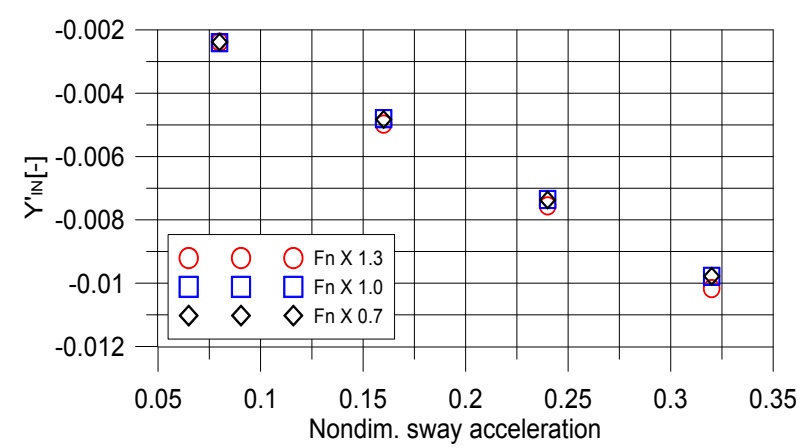

(a) Sway hydrodynamic force

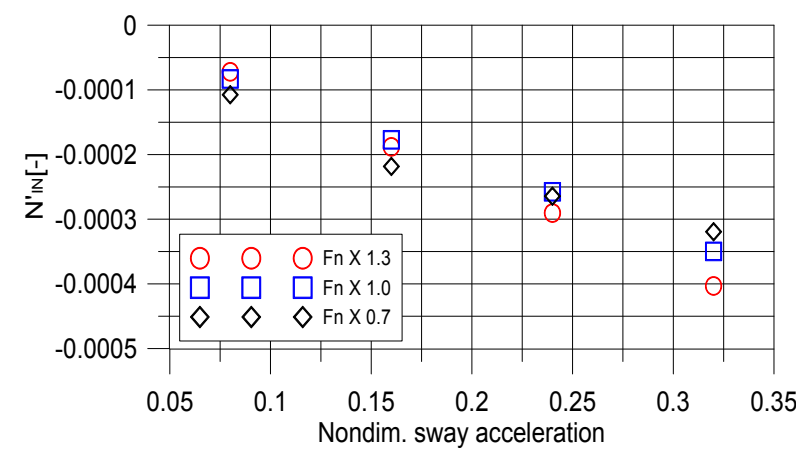

(b) Yaw hydrodynamic force

Fig. 11 Pure sway test results dependent on $F n$

The in-phase and out-of-phase hydrodynamic forces and moment to yaw motion depending on $F n$, are shown in Fig 12. There were few observed differences regarding the added mass terms; however, as $F n$ decreases, the slope the damping coefficients which were identified by out-of-phase hydrodynamic forces and moment with respect to yaw rate increases.

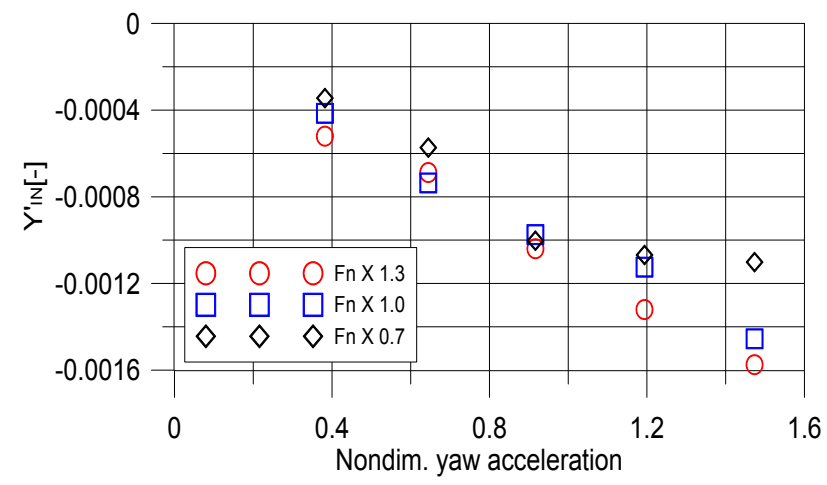

(a) In-phase sway hydrodynamic force

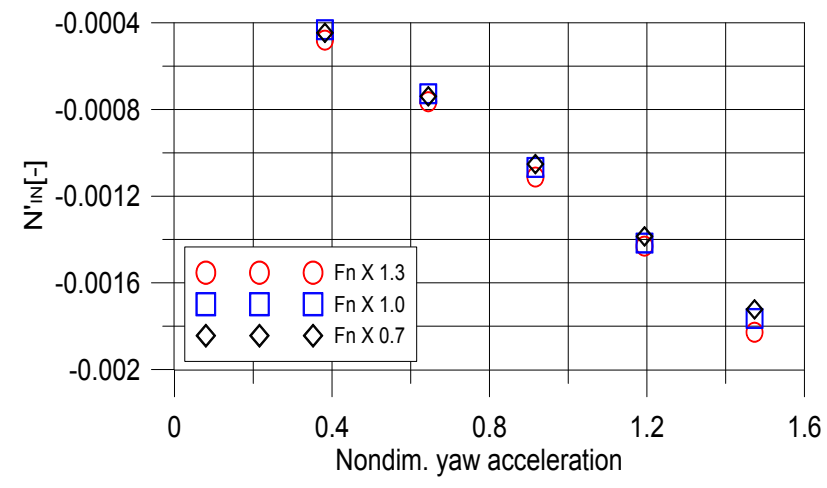

(b) In-phase yaw hydrodynamic moment 


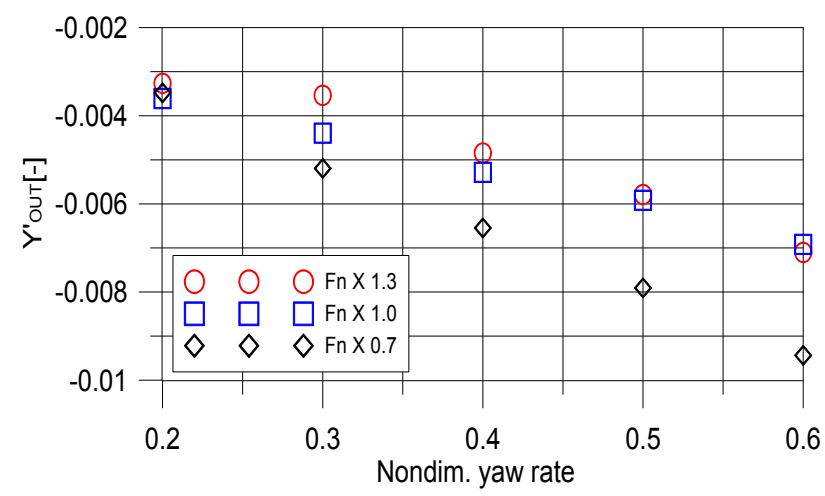

(c) Out-of-phase sway hydrodynamic force

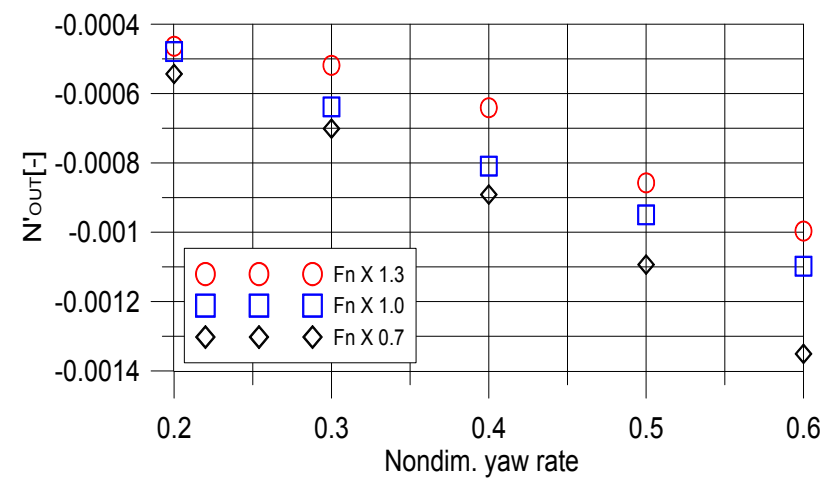

(d) Out-of-phase yaw hydrodynamic moment

Fig. 12 Pure yaw test results dependent on Fn

\section{3 $\mathrm{CM}$ test and $\mathrm{CM}$ test with drift}

The mean hydrodynamic forces and moment measured in the $\mathrm{CM}$ tests were compared to the out-of-phase hydrodynamic forces and moment measured in the PMM test. The results of each test and the results of KVLCC1 by Shin, et al. (2009) are shown together in Figs. 13 14. Since the ship shapes are different, the values of $Y^{\prime}$ and $Y_{\text {OUT }}$ of both universities are much different. Also, it can be recognized that, the forces and moment of the CM tests are considerably different from those of PMM tests. It is necessary to study more in the future.

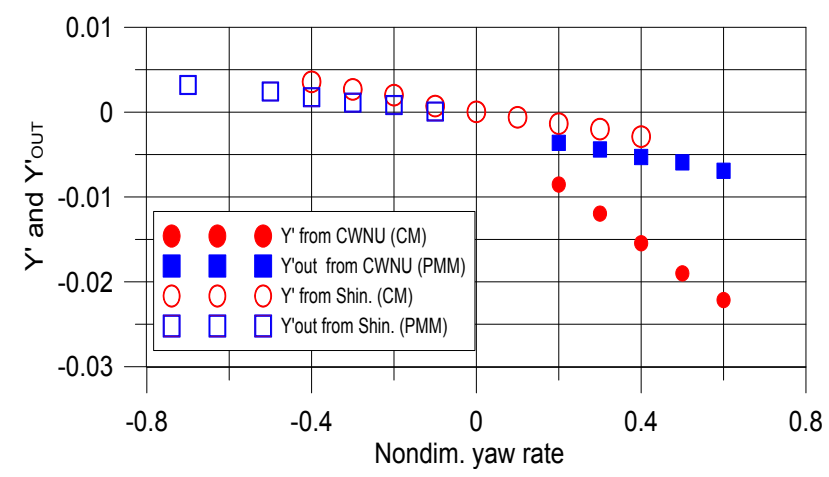

Fig. 13 Comparison of sway hydrodynamic forces

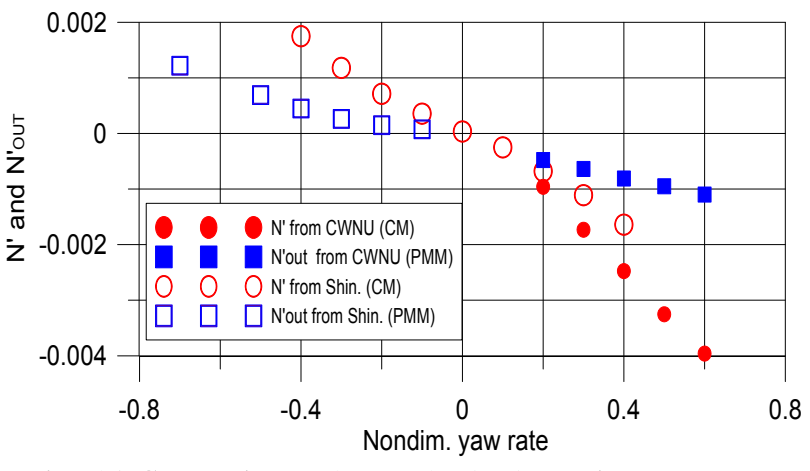

Fig. 14 Comparison of yaw hydrodynamic moments

\subsection{Hydrodynamic coefficients}

The hydrodynamic coefficients in the hydrodynamic force model depending on $F n$, described in Eq.(6), are listed in Tables $4 \sim 6$. The $F n \times 1.0$ column is the straight test case.

Table 4 Surge hydrodynamic coefficients

\begin{tabular}{|c|c|c|c|c|}
\hline Coeff. & Diagonal & Fn $\times 0.7$ & Fn $\times 1.0$ & Fn $\times 1.3$ \\
\hline$X_{v v}{ }^{\prime}$ & $-3.1638 \mathrm{E}-3$ & $-1.4285 \mathrm{E}-3$ & $-2.5168 \mathrm{E}-3$ & $-3.4879 \mathrm{E}-3$ \\
\hline$X_{r r}{ }^{\prime}$ & $2.7890 \mathrm{E}-3$ & $6.4002 \mathrm{E}-4$ & $2.8497 \mathrm{E}-3$ & $9.6816 \mathrm{E}-3$ \\
\hline$X_{v r}{ }^{\prime}$ & $1.2073 \mathrm{E}-2$ & - & $1.2017 \mathrm{E}-2$ & - \\
\hline
\end{tabular}

Table 5 Sway hydrodynamic coefficients

\begin{tabular}{|c|c|c|c|c|}
\hline Coeff. & Diagonal & Fn $\times 0.7$ & Fn $\times 1.0$ & Fn $\times 1.3$ \\
\hline$Y_{\dot{v}}^{\prime}$ & $-1.1398 \mathrm{E}-2$ & $-1.1439 \mathrm{E}-2$ & $-1.1419 \mathrm{E}-2$ & $-1.2451 \mathrm{E}-2$ \\
\hline$Y_{\dot{r}}^{\prime}$ & $-3.3540 \mathrm{E}-4$ & $-2.0040 \mathrm{E}-4$ & $-3.3935 \mathrm{E}-4$ & $-4.3525 \mathrm{E}-4$ \\
\hline$Y_{v}^{\prime}$ & $-1.9642 \mathrm{E}-2$ & $-2.0646 \mathrm{E}-2$ & $-1.8157 \mathrm{E}-2$ & $-1.6637 \mathrm{E}-2$ \\
\hline$Y_{r}^{\prime}$ & $6.0396 \mathrm{E}-3$ & $2.9880 \mathrm{E}-3$ & $6.5708 \mathrm{E}-3$ & $7.0792 \mathrm{E}-3$ \\
\hline$Y_{v v v}^{\prime}$ & $-8.5371 \mathrm{E}-2$ & $-9.5180 \mathrm{E}-2$ & $-9.2963 \mathrm{E}-2$ & $-1.0047 \mathrm{E}-1$ \\
\hline$Y_{r r r}^{\prime}$ & $-1.0053 \mathrm{E}-2$ & $5.4334 \mathrm{E}-4$ & $-1.6274 \mathrm{E}-2$ & $-1.5791 \mathrm{E}-2$ \\
\hline$Y_{v v r}^{\prime}$ & $-2.5341 \mathrm{E}-3$ & - & $1.9223 \mathrm{E}-2$ & - \\
\hline$Y_{v r r}^{\prime}$ & $-1.1131 \mathrm{E}-3$ & - & $-1.5468 \mathrm{E}-2$ & - \\
\hline
\end{tabular}

Table 6 Yaw hydrodynamic coefficients

\begin{tabular}{|c|c|c|c|c|}
\hline Coeff. & Diagonal & Fn $\times 0.7$ & Fn $\times 1.0$ & Fn $\times 1.3$ \\
\hline$N_{v}^{\prime}$ & $-3.0861 \mathrm{E}-4$ & $-4.2583 \mathrm{E}-4$ & $-4.2343 \mathrm{E}-4$ & $-5.5814 \mathrm{E}-4$ \\
\hline$N_{r}^{\prime}$ & $-8.3093 \mathrm{E}-5$ & $-5.2128 \mathrm{E}-5$ & $-7.2089 \mathrm{E}-5$ & $-1.1079 \mathrm{E}-4$ \\
\hline$N_{v}^{\prime}$ & $-6.4516 \mathrm{E}-3$ & $-6.3483 \mathrm{E}-3$ & $-6.0376 \mathrm{E}-3$ & $-6.3985 \mathrm{E}-3$ \\
\hline$N_{r}^{\prime}$ & $-9.4546 \mathrm{E}-4$ & $-1.5949 \mathrm{E}-3$ & $-1.2748 \mathrm{E}-3$ & $-1.0378 \mathrm{E}-3$ \\
\hline$N_{v v v}{ }^{\prime}$ & $4.9304 \mathrm{E}-3$ & $5.2648 \mathrm{E}-3$ & $-3.7897 \mathrm{E}-4$ & $4.0256 \mathrm{E}-3$ \\
\hline$N_{r r r}{ }^{\prime}$ & $-1.1775 \mathrm{E}-3$ & $8.7344 \mathrm{E}-4$ & $-4.6282 \mathrm{E}-4$ & $-1.5231 \mathrm{E}-3$ \\
\hline$N_{v v r}{ }^{\prime}$ & $-1.8063 \mathrm{E}-2$ & - & $-8.4752 \mathrm{E}-3$ & - \\
\hline$N_{v r r}{ }^{\prime}$ & $3.7698 \mathrm{E}-3$ & - & $2.8981 \mathrm{E}-3$ & - \\
\hline
\end{tabular}


In addition, the hydrodynamic coefficients estimated from the results of the CM test and pure yaw test together with Shin's results of the same tests for KVLCC1 are listed in Table 7. Since $Y_{r}$ is cross $^{-}$coupled derivative of which value is very small, it is difficult to estimate correctly. Also, it was guessed that the large difference between the results from two universities is because KVLCC1 was used in Shin's test. However, the ratios for $N_{r}^{\prime}$ from the pure yaw test and the CM test estimated by CWNU and Shin's results are similar.

Table 7 Comparison of hydrodynamic coefficients

\begin{tabular}{|l|l|l|r|l|l|r|}
\hline Coeff. & $\begin{array}{c}\text { CWNU } \\
\text { PMM }\end{array}$ & $\begin{array}{c}\text { CWNU } \\
\text { CM }\end{array}$ & $\begin{array}{c}\text { CM } \\
\text { /PMM }\end{array}$ & $\begin{array}{l}\text { Shin's } \\
\text { PMM }\end{array}$ & $\begin{array}{c}\text { Shin's } \\
\text { CM }\end{array}$ & $\begin{array}{c}\text { CM } \\
\text { PMM }\end{array}$ \\
\hline$Y_{r}^{\prime}$ & $6.57 \mathrm{E}-3$ & $-1.90 \mathrm{E}-2$ & -2.89 & $1.46 \mathrm{E}-2$ & $1.11 \mathrm{E}-2$ & 0.76 \\
\hline$N_{r}^{\prime}$ & $-1.27 \mathrm{E}-3$ & $-5.67 \mathrm{E}-3$ & 4.46 & $-7.74 \mathrm{E}-4$ & $-3.31 \mathrm{E}-3$ & 4.28 \\
\hline
\end{tabular}

\section{Conclusions}

In this paper, diverse tests were performed to verify the feasibility and utilization of the square tank at CWNU for obtaining the hydrodynamic coefficients which are inevitable to estimate ship maneuverability.

The results of the diagonal and straight PMM tests are consistent each other. This indicates that conducting diagonal PMM testing to extend the running length instead of straight PMM testing provides satisfactory results. However, the slight difference between two results should be confirmed by the investigation on PMM running time history and loadcell's characteristics.

The hydrodynamic forces and moment due to the change of the Froude number are nearly identical, except for large drift angles and yaw damping coefficients. If the differences in large ranges of motion can be neglected, more varied types of model ships which cannot adjust the real ship's Fn could be used for PMM testing in small-scale tank.

Finally, the results of the PMM test and the CM test are not consistent well even in $N_{r}$ coefficient. To find out the cause of these results, more tests would be necessary in future.

\section{Acknowledgement}

This work was supported by the project "Development of small leisure boat handling 3D simulator," which was sponsored by the Ministry of Trade, Industry \& Energy, Korea and "Changwon National University in 2013 2014".

\section{References}

[1] Kim, D. J. (2012), "A study on the running attitude and dynamic stability of a semi-displacement round bilge vessel at high speed", $\mathrm{PhD}$ thesis, Seoul National University.

[2] Kim, Y. G., Yeo, D. J., Kim, S. Y., Yun, K. H. and Oh, B. I. (2009), "Prediction of Maneuverability of KCS by CPMC Captive Model Test", Journal of the Society of Naval Architects of Korea, Vol. 46, No. 6, pp. 553-561

[3] Kim, Y. G., Yeo, D. J., Son, N. S., Kim, S. Y., Yun, K H. and Oh, B. I. (2011), "Prediction of Maneuverability of KCS with 4 Degrees of Freedom", Journal of the Society of Naval Architects of Korea, Vol. 48, No. 3, pp. 267-274.

[4] Shin, H. K., Jung, J. H. and Lee, H. Y. (2009), "Prediction of Ship Manoeuvrability by Circular Motion Test", Journal of the Society of Naval Architects of Korea, Vol. 46, No. 3, pp. 259-267.

[5] Shin, H. K. and Choi, S. H. (2011) "Prediction of Ship Maneuverability of KCS Using Captive Model test", Journal of the Society of Naval Architects of Korea, Vol. 46, No. 3, pp. 465-472.

[6] SIMMAN. (2008), http://www.simman2008.dk/KVLCC/ KVLCC2/kvlcc2_test_program.htm.

[7] Tajima, S. I., Ikeda, Y., Katayama, T. and Okumura, H. (1999), "Measurements of Hydrodynamic Forces Acting on Planing Hull at High-Speed by Planar Motion Mechanism Test", Journal of the Kansai Society of Naval Architects, Japan, No. 232, pp. 71-75.

[8] Yoon, H. K. and Kang, S. (2013), "Experimental Investigation on the Depth Effect of Hydrodynamic Coefficients Obtained by PMM Test in Square Tank", 3rd International Conference on Ship Manoeuvring in Shallow Water and Confined Water.

Received 3 February 2014

Revised 26 February 2014

Accepted 27 February 2014 